\title{
Externalizing Problems Composite Score
}

National Cancer Institute

\section{Source}

National Cancer Institute. Externalizing Problems Composite Score. NCI Thesaurus. Code C121300.

A composite score of the Behavior Assessment System for Children that combines the hyperactivity, aggression, and conduct problems scales. This composite score measures disruptive behavior problems. 